\title{
Invasive Tall Cell Variant of Papillary Cancer originating from the Pyramidal Lobe of the Thyroid Gland with Extension to the Base of the Tongue
}

\author{
${ }^{1}$ Elena M Wagner, ${ }^{2}$ Santhi Ganesan, ${ }^{3}$ Christopher R McHenry
}

\begin{abstract}
A pyramidal lobe of the thyroid gland is a common anatomic variant. However, primary malignancy of the pyramidal lobe is rare with the exception of cancer in a thyroglossal duct cyst. A 61-year-old morbidly obese woman presented with a $30 \mathrm{lb}$. weight loss and a large asymptomatic submental neck mass that extended to the base of her tongue. The mass was invading the hyoid bone and the sternohyoid muscles. The patient had a short thick neck and "double chin," which lead to delay in recognition of the neck mass. Further workup and final pathology revealed a locally invasive, tall cell variant of papillary cancer arising from the pyramidal lobe of the thyroid gland with regional and systemic metastases. To our knowledge, this is only the second case of a thyroid cancer arising from a pyramidal lobe reported in the literature. Primary thyroid cancer arising from the pyramidal lobe should be considered in the differential diagnosis of a midline neck mass.
\end{abstract}

Keywords: Papillary thyroid cancer, Invasive tall cell variant, Pyramidal lobe.

How to cite this article: Wagner EM, Ganesan S, McHenry CR. Invasive Tall Cell Variant of Papillary Cancer originating from the Pyramidal Lobe of the Thyroid Gland with Extension to the Base of the Tongue. World J Endoc Surg 2014;6(1):7-10.

Source of support: Nil

Conflict of interest: None

\section{INTRODUCTION}

The pyramidal lobe of the thyroid gland develops from the remnant of the thyroglossal duct, an epithelial tract which forms from a midline endodermal evagination in the floor of the pharynx at the 3rd week of embryologic development. The thyroglossal duct descends and reaches its final destination in the neck at the 7th week of embrylogic development. The central portion of the thyroid gland develops from the distal end of thyroglossal duct. The remainder of the thyroglossal duct atrophies and involutes by the 9 th to 10 th weeks of gestation.

\footnotetext{
${ }^{1}$ Medical Student, ${ }^{2}$ Assistant Professor, ${ }^{3}$ Vice Chairperson

1,3 Department of Surgery, MetroHealth Medical Center, Cleveland Ohio, USA

${ }^{2}$ Department of Pathology, MetroHealth Medical Center Cleveland, Ohio, USA
}

Corresponding Author: Christopher R McHenry, Vice Chairperson, Department of Surgery, MetroHealth Medical Center Cleveland, Ohio, USA, e-mail: cmchenry@metrohealth.org
When the thyroglossal duct fails to involute, it may persist and form a pyramidal lobe of the thyroid gland. Endodermal cells commonly line the thyroglossal duct and are a source of mucus production and thyroglossal duct cyst formation. A primary malignancy arising from the pyramidal lobe of the thyroid gland is rare. Herein, we report only the second case of a primary malignancy arising from the pyramidal lobe of the thyroid gland that extended to the base of the tongue and invaded the hyoid bone and skeletal muscle.

\section{Case Report}

A 62-year-old woman was referred for evaluation of a large neck mass. She complained of a swelling under her chin that was most prominent when she extended her neck. It was unclear how long the mass had been present. She reported a $30 \mathrm{lb}$. unintentional weight loss over 15 months. Otherwise, she was asymptomatic. She had no prior history of head or neck radiation and there was no family history of thyroid cancer or other endocrinopathies.

Physical examination revealed a morbidly obese woman with a body mass index of $42 \mathrm{~kg} / \mathrm{m}^{2}$. She had an $8 \times 5 \mathrm{~cm}$ midline neck mass extending from just below the cricoid cartilage to just above the hyoid bone (Fig. 1A) that was obscured from visualization by a short thick neck and a large chin with abundant sagging subcutaneous fat and lax skin (double chin). There was no palpable lymphadenopathy. The remainder of the exam was unremarkable.

An ultrasound examination of the neck showed a large, heterogeneous submental mass in the midline of the upper neck measuring $4.7 \times 3.3 \times 5.1 \mathrm{~cm}$. Computed tomography of the neck revealed that the mass was just superior to the thyroid isthmus and it was causing destruction of the hyoid bone (Fig. 1B). Additionally, there was a $1.5 \mathrm{~cm}$ left submandibular lymph node. Her serum thyroid stimulating hormone (TSH) level was $1.642 \mathrm{uIU} / \mathrm{ml}$. Fine needle aspiration biopsy of the mass and the enlarged lymph node revealed papillary thyroid cancer.

At operation, the patient was found to have a $6.5 \times 4.5 \times$ $3.7 \mathrm{~cm}$ tumor, arising from the pyramidal lobe of the thyroid gland and extending to the base of the tongue. It was infiltrating the sternohyoid muscle and the hyoid bone. The remainder of the thyroid gland appeared normal and there 

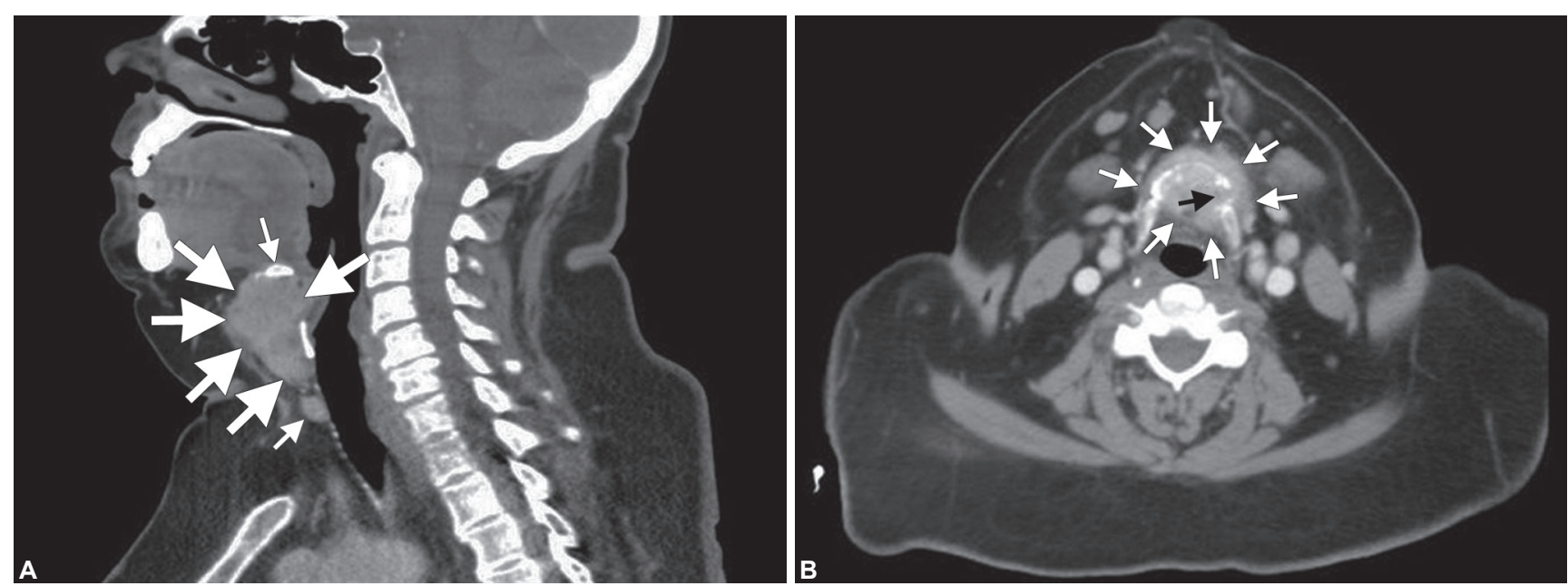

Figs 1A and B: (A) Sagittal computed tomography image showing large midline mass (thick arrows) extending from hyoid bone (thin arrow) to just superior to isthmus of thyroid (thin arrow) and (B) computed tomography image demonstrating midline mass (white arrows) with destruction of hyoid bone (black arrow)

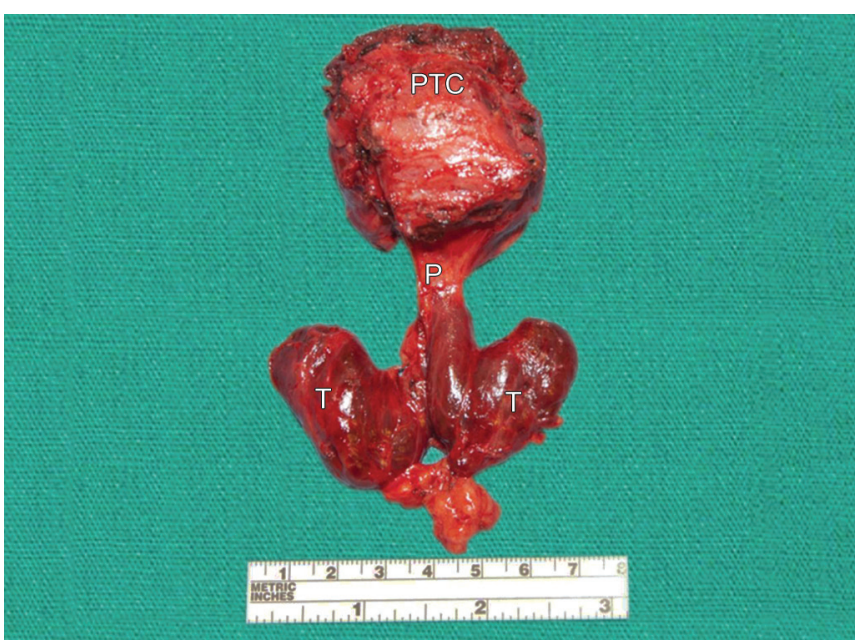

Fig. 2: Surgical specimen with papillary thyroid cancer arising from the apex of the pyramidal lobe $(P)$ along with the right and left lobes of the thyroid $(\mathrm{T})$

were no abnormal lymph nodes seen in the central neck. An en bloc resection of the tumor, the skeletal muscle, the hyoid bone, adjacent prelaryngeal lymph nodes, and the remainder of the thyroid gland with some adjacent perithyroidal lymph nodes were completed (Fig. 2). An assistant inserted a finger in the patient's oral cavity and applied downward pressure on the base of the tongue, which facilitated resection of the proximal extent of the tumor. A subsequent compartmentoriented removal of levels II, III, and IV lymph nodes from the left neck was completed. Ultrasound was used to help identify the nonpalpable, sonographically abnormal submandibular lymph node, and the overlying skin was marked to help facilitate intraoperative localization.

Pathologic evaluation revealed a moderately differentiated, tall cell variant of papillary carcinoma arising from the pyramidal lobe of the thyroid gland infiltrating the surrounding fibroadipose tissue, skeletal muscle, and hyoid bone (Figs 3A to D). The anterior soft tissue margin was involved with carcinoma. The remaining thyroid tissue had no significant pathological features and five perithyroidal lymph nodes were negative for tumor. One of 13 lateral lymph nodes was involved with metastatic carcinoma.

Postoperatively, the patient was treated with $150 \mathrm{mCi}$ of iodine 131 and a posttreatment whole body scan revealed no abnormal uptake. A TSH stimulated thyroglobin was $1017 \mathrm{ng} / \mathrm{mL}$. She was started on a suppressive dose of levothyroxine to maintain her serum TSH level less than $0.1 \mathrm{uIU} / \mathrm{mL}$. A computed tomogram of the chest revealed innumerable bilateral miliary pulmonary nodules. Magnetic imaging of the brain revealed no evidence of metastases. The patient subsequently underwent intensity modulated radiation therapy to the neck with plans for treatment with a tyrosine-kinase inhibitor should the pulmonary nodules progress to be $>1 \mathrm{~cm}$ in size.

\section{DISCUSSION}

The pyramidal lobe of the thyroid gland is a common anatomical variant of the thyroid gland with a prevalence of $29-61 \%{ }^{1-10}$ Despite the significant prevalence of a pyramidal lobe of the thyroid gland, tumors of the pyramidal lobe are rare. Excluding carcinoma arising in a thyroglossal duct cyst, to our knowledge there is only one other reported case in the literature of thyroid carcinoma arising from the pyramidal lobe. Ogawa et al, ${ }^{11}$ described a 21 -year-old woman with a $3.5 \mathrm{~cm}$ minimally-invasive follicular cancer arising from the apex of the pyramidal lobe, similar in location to our patient's tumor.

In contrast to the case reported by Ogawa et al, our patient had an aggressive tall cell variant of papillary cancer that was radioiodine resistant with extrathyroidal tumor spread, lymph node metastasis and pulmonary metastases. The absence of symptoms, morbid obesity, and the patient's 

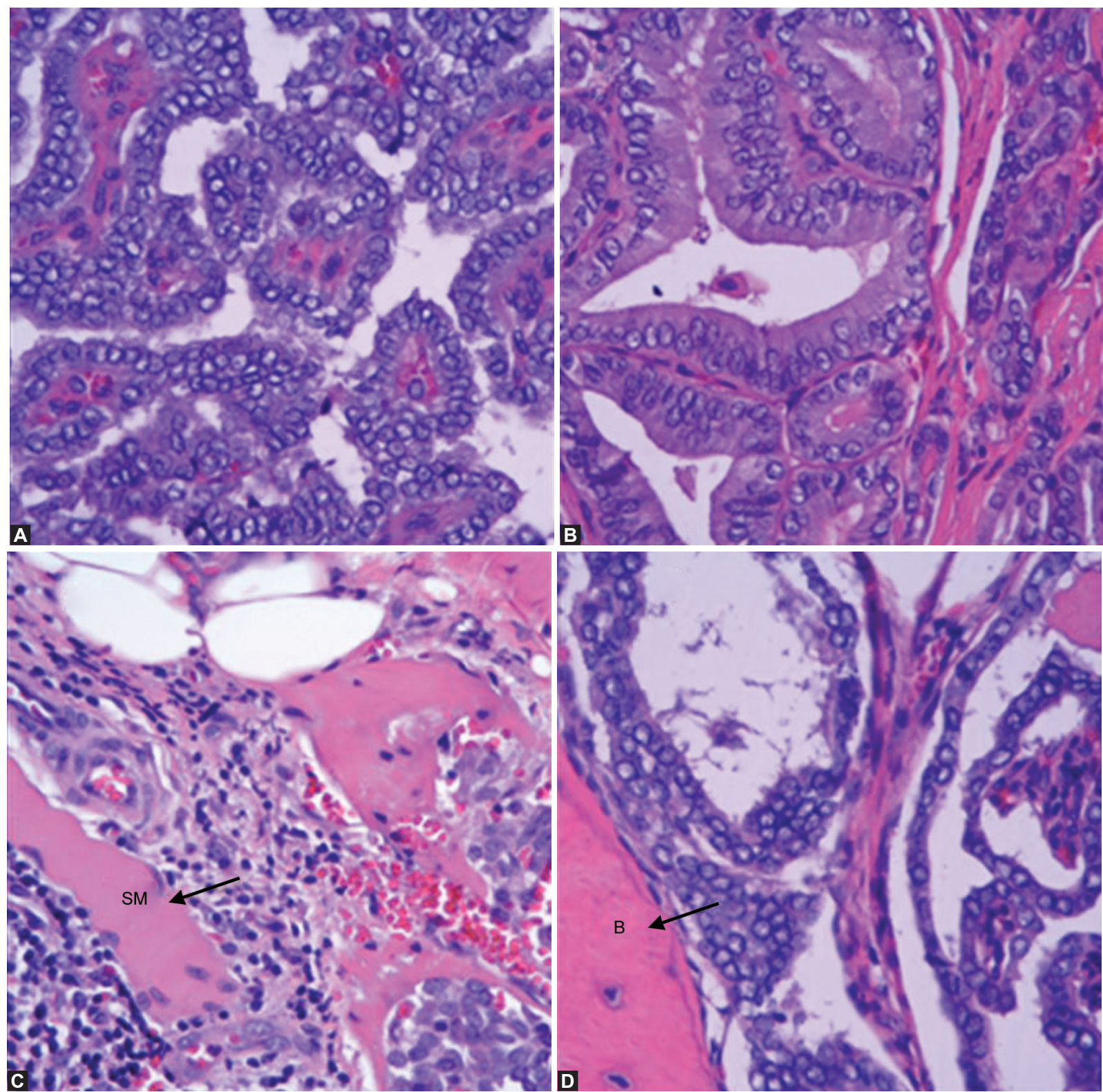

Figs $3 A$ to $D$ : $(A)$ Microscopically, the tumor is comprised of numerous true papillae with prominent fibrovascular cores and complex branching. The tumor cells demonstrate optically clear nuclei with frequent nuclear grooves and overlap, (B) there were prominent papillary fronds lined by a distinct, single layer of "tall" cells (height two times the width) and abundant eosinophilic and oncocytoid cytoplasm, and ( $C$ and $D)$ there was widespread invasion into the surrounding skeletal muscle and the hyoid bone (B)

short thick neck and double chin likely contributed to a prolonged delay in recognition of her tumor. This is supported by the $30 \mathrm{lb}$ unintentional weight loss she experienced over 15 months, which is an uncommon manifestation of differentiated thyroid cancer.

The pyramidal lobe is more commonly involved by direct tumor extension from one of the lobes of the thyroid gland or a site of recurrence when incomplete thyroidectomy is performed. In a review of 1,405 patients with thyroid cancer, Sturniolo et $\mathrm{al}^{12}$ in reported involvement of the pyramidal lobe in 44 cases. In all cases, the cancer originated from a main lobe of the thyroid gland and then invaded or recurred in the pyramidal lobe. In contrast, our patient's cancer arose directly from the pyramidal lobe. Lee et $\mathrm{al}^{13}$ described a patient with papillary thyroid cancer that recurred in the pyramidal lobe 1 year after endoscopic total thyroidectomy.

Another possibility that must be considered when evaluating a midline neck mass is a thyroglossal duct cyst. An associated malignancy has been reported to occur in approximately $1 \%$ of patients with a thyroglossal duct cyst and papillary cancer is the most common histologic variant. ${ }^{14}$ It is conceivable that our patient's malignancy could have arisen from a thyroglossal duct cyst, but the pathologic evaluation did not support this. There was no cystic component of the tumor. Instead, the tumor arose directly from the pyramidal lobe. Thus, the pyramidal lobe can give rise to a primary invasive cancer and this possibility should always be considered in the differential diagnosis of a midline neck mass. 


\section{REFERENCES}

1. Braun EM1, Windisch G, Wolf G, Hausleitner L, Anderhuber F. The pyramidal lobe: clinical anatomy and its importance in thyroid surgery. Surg Radiol Anat 2007 Feb;29(1):21-27.

2. Bergmann, RA.; Thompson, SA.; Afifi, AK. Compendium of human anatomic variation: Tart, atlas, and world literature. Baltimore: Urban \& Schwarzenberg; 1988. 175 p.

3. Tanriover O, Comunoglu N, Eren B, Comunoglu C, Turkmen N, Bilgen S, Kaspar EC, Gündogmus UN. Morphometric features of the thyroid gland: a cadaveric study of Turkish people. Folia Morphol (Warsz) 2011 May;70(2):103-108.

4. Sultana S, Mannan S, Ahmed M, Rahman M, Khan M, Khalil M. An anatomical study on pyramidal lobe of thyroid gland in Bangladeshi people. Mymensingh Med J 2008 Jan;17(1):8-13.

5. Ozgur Z, Celik S, Govsa F, Ozgur T. Anatomical and surgical aspects of the lobes of the thyroid glands. Eur Arch Otorhinolaryngol 2011 Sep;268(9):1357-1363.

6. Joshi SD, Joshi SS, Daimi SR, Athavale SA. The thyroid gland and its variations: a cadaveric study. Folia Morphol (Warsz) 2010 Feb;69(1):47-50.

7. Zivic R, Radovanovic D, Vekic B, Markovic I, Dzodic R, Zivaljevic $\mathrm{V}$. Surgical anatomy of the pyramidal lobe and its significance in thyroid surgery. S Afr J Surg 2011 Aug 31;49(3):110, 112, 114 passim.

8. Harjeet A, Sahni D, Jit I, Aggarwal AK. Shape, measurements and weight of the thyroid gland in northwest Indians. Surg Radiol Anat 2004 Apr;26(2):91-95.

9. Ranade AV, Rai R, Pai MM, Nayak SR, Prakash, Krisnamurthy A, Narayana S. Anatomical variations of the thyroid gland: possible surgical implications. Singapore Med J 2008 Oct;49(10):831-834.

10. Blumberg NA. Observations on the pyramidal lobe of the thyroid gland. S Afr Med J 1981 Jun 20;59(26):949-950.

11. Ogawa C, Kammori M, Onose H, Yamada E, Shimizu K, Yamada T. Follicular carcinoma arising from the pyramidal lobe of the thyroid. J Nippon Med Sch 2009 Jun;76(3):169-172.

12. Sturniolo G, Bonanno L, Gagliano E, Tonante A, Taranto F, Mamo M, De Salvo G, Sturnioloa G. [The thyroid pyramidal lobe: frequency, morphological features and related diseases]. Chir Ital 2008 Jan-Feb;60(1):41-46.

13. Lee YS, Kim KJ, Kim BW, Chang HS, Park CS. Recurrence of papillary thyroid carcinoma in a remnant pyramidal lobe. ANZ J Surg 2011 Apr;81(4):304.

14. Renard TH, Choucair RJ, Stevenson WD, Brooks WC, Poulos E. Carcinoma of the thyroglossal duct. Surg Gynecol Obstet 1990 Oct;171(4):305-308. 